\title{
PATTERN OF SALIVARY GLAND TUMOURS IN A TERTIARY CARE HOSPITAL IN NORTH EASTERN INDIA
}

\author{
Linadri Kalita ${ }^{1}$, Ananta Kumar Nath²
}

${ }^{1}$ Registrar, Department of ENT, Jorhat Medical College and Hospital.

${ }^{2}$ Registrar, Department of Paediatrics, Jorhat Medical College and Hospital.

\begin{tabular}{l}
\hline ABSTRACT \\
BACKGROUND \\
Though rare, salivary gland tumours represent $6 \%$ of all head and neck neoplasm. ${ }^{1}$ These tumours got so much important because \\
of their diverse array of clinical presentation, behaviour, histopathology, close proximity to major vessels and engulfment of facial \\
nerve.
\end{tabular}

OBJECTIVES

To evaluate the pattern of various salivary gland tumours and their management pattern in a tertiary health care centre in North Eastern India.

\section{DESIGN}

Prospective Cohort Study.

\section{SETTING}

Dept. of Otorhinolaryngology (ENT), Silchar Medical College and Hospital, Assam.

\section{MATERIALS AND METHODS}

After ethical clearance all patients with salivary gland tumours, admitted to the Dept. of ENT from August 2013 to July 2014, were included in the study. A specially designed questionnaire was used to assess the presenting history, clinical presentation, size, consistency, pain, involvement to surrounding structures were noted. FNAC and sample for biopsy were taken and sent for Histopathological Examination. After surgery, the patients were observed for complication. Radiotherapy was given whenever needed.

\section{RESULTS}

Over a period of 1 year, a total of 40 cases with salivary gland tumours were studied. With age range from 11 years to 70 years, this study showed overall slight female preponderance $(\mathrm{M}: \mathrm{F}=1: 1.5)$. Parotid gland $(87.5 \%)$ was found to be a commonest gland involved followed by submandibular gland $(10.0 \%)$ and minor salivary gland $(2.5 \%)$. Benign tumours were found to be $77.5 \%$ of cases and malignant lesions constituted $22.5 \%$ cases. Pleomorphic adenoma was the commonest benign neoplastic lesion (67.5\%) and mucoepidermoid carcinoma was the commonest malignant tumour (20\%). All patients (100\%) with salivary gland tumour presented with swelling and superficial parotidectomy was the commonest (52.5\%) procedure followed during treatment.

\section{CONCLUSION}

Parotid gland was found to be the principal site for salivary gland tumour and pleomorphic adenoma was found to be the most common tumour among the patients. Females were more affected both in the benign and malignant group.

\section{KEYWORDS}

Salivary Gland, Parotid Gland, Submandibular Gland, Pleomorphic Adenoma.

HOW TO CITE THIS ARTICLE: Kalita L, Nath AK. Pattern of salivary gland tumours in a tertiary care hospital in North Eastern India. J. Evolution Med. Dent. Sci. 2016;5(66):4699-4702, DOI: 10.14260/jemds/2016/1071

\section{INTRODUCTION}

Salivary gland neoplasms pose a great challenge to head and neck surgeons. Their diagnosis and treatment are quite difficult, because they are relatively infrequent and show wide pathological variety. Different salivary gland tumours show different morphological features. Sometimes benign tumours show malignant change making diagnosis more difficult.

Financial or Other, Competing Interest: None.

Submission 11-07-2016, Peer Review 04-08-2016,

Acceptance 10-08-2016, Published 16-08-2016.

Corresponding Author:

Dr. Linadri Kalita,

Department of ENT,

Jorhat Medical College and Hospital,

Jail Road, Jorhat, Assam-785001.

E-mail: dreamyou85@gmail.com

DOI: $10.14260 /$ jemds/2016/1071
Pre-operative fine needle aspiration cytology aids in diagnosis and helps in management. Salivary gland neoplasms are rare, constitute $6 \%$ of head and neck tumours. ${ }^{1}$ Among the primary epithelial tumours, $64-80 \%$ occur in the parotid glands, $7-11 \%$ occur in the sub-mandibular, less than $1 \%$ occur in the sublingual and $9-23 \%$ occur in the minor salivary glands. ${ }^{2}$

Salivary gland tumours grow gradually. Patients usually give history of long-standing mass, gradually increasing in size. There is difference of opinion among surgeons regarding treatment of salivary gland tumours. To plan the treatment and to prepare for surgery or radiotherapy, it is important to detect benign and malignant salivary gland tumours preoperatively. Some of the very important nerves lie in relation to salivary gland injury, which may result in devastating consequences. Hence, management of salivary gland tumours require good 
preoperative assessment, good knowledge of anatomy and surgical skill. The salivary gland tumours are mostly treated by surgery. Only a few malignant tumours undergo radiotherapy. The type of surgery varies with morphological type of the tumour, which means the extent of surgical excision will depend on the type of tumour. Here is a prospective study with the aim to study the clinical presentation of various salivary gland tumours and their surgical management.

\section{MATERIAL AND METHODS}

A prospective cohort study was conducted for a period of one year from $1^{\text {st }}$ August 2013 to $31^{\text {st }}$ July 2014 in the Department of ENT, Silchar Medical College and Hospital, a tertiary care hospital in North Eastern India.

After Ethical Clearance from Hospital Ethical Committee, a total of forty cases of salivary gland tumours who got admitted during this period were included in the study.

\section{Inclusion Criteria}

- All patients admitted to Department of ENT, Silchar Medical College and Hospital with signs and symptoms of salivary gland tumours.

\section{Exclusion Criteria}

- Inflammatory swelling of salivary gland.

- Cystic swelling of salivary gland or swelling with cystic component.

- $\quad$ Non-neoplastic swellings of the salivary glands.

- Patients refusing for surgical treatment.

All of these patients were admitted and properly evaluated by the detail history, thorough clinical examination, routine laboratory investigations and specific investigations whatever necessary. In history, importance was given to presenting complaints, duration and size of the lump, increase in size with its speed (whether rapid or slow), associated symptoms of facial nerve involvement, previous history of surgery or any medical problem.

Regarding physical examination, particulars mentioned in the proforma were noted. Importance was given to the site, extent of the tumour, deep lobe enlargement and fixity to the underlying as well as surrounding structures, nerve involvement and regional lymphadenopathy. Associated medical conditions like diabetes, hypertension and anaemia were managed and controlled before surgery with physician's advice. As a part of general work up for surgery in all patients, haemoglobin level, urine, sugar, albumin, bleeding time, clotting time, ECG, chest screening, serum creatinine, blood urea, RBS were estimated. Specific investigations like FNAC, Xray of mandible were done for all patients in the study group.

After evaluation of the tumour by clinical examination and specific investigations, a surgical plan was formulated. The final decision was taken per operatively by the surgeon. The specimen was sent for Histopathological Examination (HPE). Appropriate antibiotics and analgesics were administered post operatively for all cases. Drainage tube was removed on 3rd day and sutures on $5^{\text {th }}$ day. After surgery, malignant tumours were referred to Dept. of Radiotherapy, for postoperative radiotherapy. The adjuvant treatment was decided depending on the final HPE report.
Different Modalities of Treatment Adopted during this Study are

1. Surgery alone.

2. Surgery and postoperative radiotherapy.

The follow-up period of these patients ranged from 3 months to 1 year. All patients were asked for follow-up after 15 days of surgery, then every month for first year, then every 3 months in second year to detect morbidity and recurrence. Long term follow-up is necessary to study the tumour recurrence, which was not possible in this study.

\section{OBSERVATION}

Study was done over a period of one year and within this year 40 cases with salivary gland tumours were enrolled for this study.

Among these 40 cases, most of the tumours were found to be in the age group of 31-40 years (27.5\%) followed by $41-50$ years $(20 \%)$ and $51-60$ years $(20 \%)$. Benign tumours were much more common (77.5\%) than malignant tumours (22.5\%). Out of malignant tumours, maximum number was found to be in the age group of 51-60 years (33.3\%).

Male-female ratio was 1:1.5 among all salivary gland neoplasm. Regarding benign tumour male female ratio was $1: 1.58$ and malignant tumour, this ratio was found to be1:1.25. (Table 1).

Out of all cases, parotid gland submandibular gland and minor salivary gland involvement were seen in $87.5 \%, 10 \%$ and $2.5 \%$ respectively. Among all parotid tumour, $77.15 \%$ cases were benign and $22.85 \%$ were malignant. In submandibular gland lesion $75 \%$ cases were benign and rest $25 \%$ cases were malignant in nature. Minor salivary gland involved lesion was benign in nature. (Table 2).

About the presentation all cases of salivary gland neoplasm presented with swelling (100\%); 15\% cases presented with pain with swelling, $5 \%$ presented with facial nerve palsy with swelling. Only $2.5 \%$ cases presented with cervical node with swelling.

When it comes to the size, out of total cases $32.5 \%$ cases were of size less than $5 \mathrm{~cm}$ in size, $60 \%$ were $5-10 \mathrm{~cm}$ in size and $7.5 \%$ cases were more than $10 \mathrm{~cm}$ in size.

On examination all the benign cases were firm in consistency. Out of 9 malignant cases $55.6 \%$ were firm and $44.4 \%$ were hard in consistency. Tenderness is elicited in $10 \%$ cases which were malignant. Deep lobe involvement was seen in $2.5 \%$ benign and $2.5 \%$ malignant cases. Facial nerve was involved in $5 \%$ malignant cases. Only $2.5 \%$ malignant case presented with lymph node involvement. None of the patients presented with metastasis.

About the type of tumour $67.5 \%$ lesions were pleomorphic adenoma, 20\% mucoepidermoid carcinoma and $7.5 \%$ tumours were Warthin's tumour. 2.5\% cases were found to be Basal Cell Adenoma and another $2.5 \%$ were found to be Adenoid Cystic Carcinoma (Table 3).

During treatment $12.5 \%$ cases had undergone enucleation procedure and $52.5 \%$ cases had undergone Superficial Parotidectomy. Total Parotidectomy done in 20\% cases. Radical Parotidectomy with neck dissection was done in $2.5 \%$ cases .Total Excision was done in $12.5 \%$ cases.

After surgical procedure temporary Facial nerve palsy was seen in $20 \%$ of cases while permanent palsy in $2.5 \%$ of cases. $5 \%$ cases had post-operative wound infection.

Frey's syndrome was seen in $7.5 \%$ of cases. Haemorrhage encountered in $5 \%$ cases. Skin flap necrosis developed in only $2.5 \%$ cases. None of the patients developed fistula. 
No recurrence has been found during the course of the study. Salivary gland tumours require long-term follow-up, which was not possible in this study.

\begin{tabular}{|c|c|c|c|c|}
\hline Sex & $\begin{array}{c}\text { Benign } \\
\text { Tumour }\end{array}$ & $\begin{array}{c}\text { Malignant } \\
\text { Tumour }\end{array}$ & $\begin{array}{c}\text { Total No. of } \\
\text { Patients }\end{array}$ & $\begin{array}{c}\text { \% of } \\
\text { Total }\end{array}$ \\
\hline Male & 12 & 4 & 16 & 40 \\
\hline Female & 19 & 5 & 24 & 60 \\
\hline Total & $\mathbf{3 1}$ & $\mathbf{9}$ & $\mathbf{4 0}$ & $\mathbf{1 0 0}$ \\
\hline
\end{tabular}

Table 1: Tumour Distribution According to Sex

\begin{tabular}{|c|c|c|c|c|}
\hline $\begin{array}{c}\text { Salivary } \\
\text { Gland }\end{array}$ & $\begin{array}{c}\text { Benign } \\
\text { Tumour }\end{array}$ & $\begin{array}{c}\text { Malignant } \\
\text { Tumour }\end{array}$ & $\begin{array}{c}\text { Total } \\
\text { No. of } \\
\text { Patients }\end{array}$ & $\begin{array}{c}\text { \% of } \\
\text { Total }\end{array}$ \\
\hline Parotid gland & 27 & 8 & 35 & 87.5 \\
\hline $\begin{array}{c}\text { Submandibular } \\
\text { gland }\end{array}$ & 3 & 1 & 4 & 10 \\
\hline $\begin{array}{c}\text { Minor salivary } \\
\text { gland }\end{array}$ & 1 & 0 & 1 & 2.5 \\
\hline Total & $\mathbf{3 1}$ & $\mathbf{9}$ & $\mathbf{4 0}$ & $\mathbf{1 0 0}$ \\
\hline \multicolumn{4}{|r|}{ Table 2: Tumour Distribution According to Site } \\
\hline
\end{tabular}

\begin{tabular}{|c|c|c|}
\hline $\begin{array}{c}\text { Histopathological } \\
\text { Types }\end{array}$ & $\begin{array}{c}\text { No. of } \\
\text { Patients }\end{array}$ & $\begin{array}{l}\text { \% of } \\
\text { Total }\end{array}$ \\
\hline $\begin{array}{l}\text { Pleomorphic } \\
\text { Adenoma }\end{array}$ & 27 & 67.5 \\
\hline $\begin{array}{l}\text { Mucoepidermoid } \\
\text { Carcinoma }\end{array}$ & 8 & 20 \\
\hline Warthin's tumour & 3 & 7.5 \\
\hline Basal Cell Adenoma & 1 & 2.5 \\
\hline $\begin{array}{l}\text { Adenoid Cystic } \\
\text { Carcinoma }\end{array}$ & 1 & 2.5 \\
\hline Total & 40 & 100 \\
\hline \multicolumn{3}{|c|}{$\begin{array}{c}\text { Table 3: Various Histopathological Types } \\
\text { of Salivary Gland Tumours }\end{array}$} \\
\hline
\end{tabular}

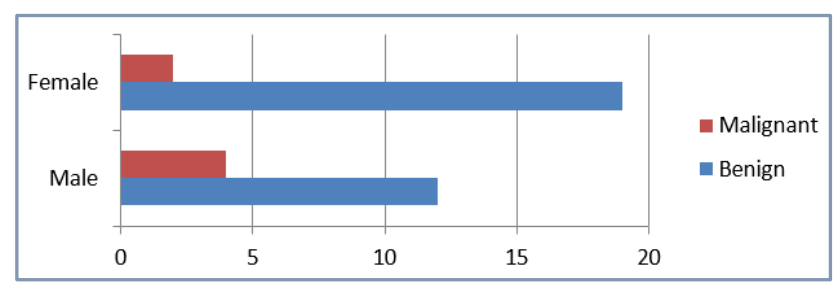

Fig. 1: Tumour Distribution According to Sex

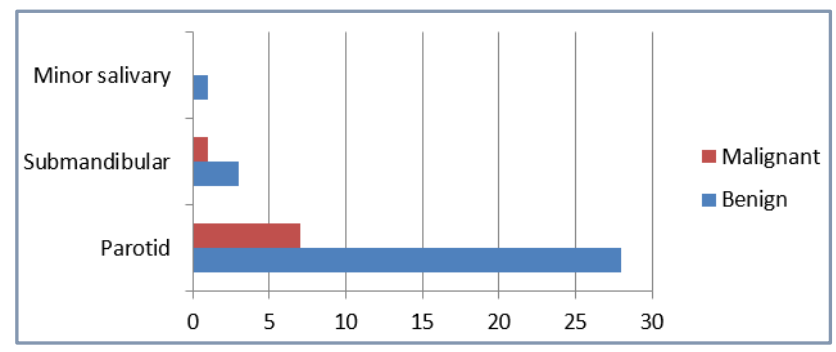

Fig. 2: Tumour Distribution According to Site

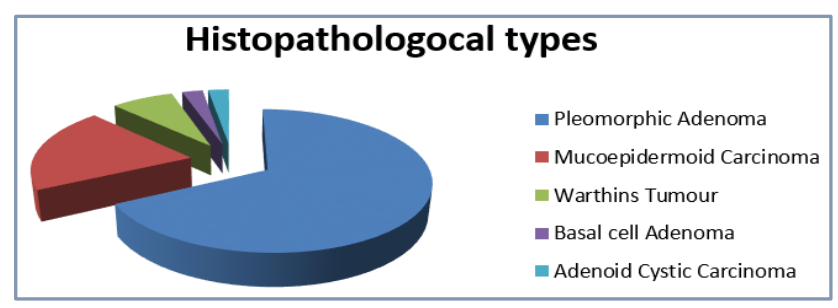

Fig. 3: Histopathological Types of Salivary Gland Tumour

\section{DISCUSSION}

This study was done to evaluate the spectrum of presentation, type and treatment protocol in cases of salivary gland tumours in this region of North East, as there were limited studies in North Eastern region and specially there were a very few published data from Assam. Though salivary gland tumours are uncommon tumour, but over a period of one year we encountered 40 cases which can at least enlighten the disease spectrum in this region.

In this study a short series of 40 cases of salivary gland tumours, which were admitted to the Dept. of ENT, Silchar Medical College and Hospital during the period August 2013 to July 2014 were studied. Detailed analysis has been done and has been compared with statistics available from Indian and other authors of the world.

In the present study, it was observed that average age in year for benign lesion was 36 and for malignant lesion was 43 . In a study by Li Long Jiang Jiang et al, average age in year for benign lesion and malignant lesion was 41.38 and 45.20 years respectively. ${ }^{3}$ Another study by Eveson JW and Cawson RA, average age in year for benign lesion and malignant lesion was 55 and 65 years respectively. ${ }^{4}$ Early exposure to carcinogen may be the possible explanation for this in this region. It is seen that in most studies, benign tumour occurs at younger age group than malignant tumour. Salivary gland malignancies present at an earlier age than most other malignancies.

In the present study among all cases, male-to-female ratio was around 1:1.5. Study by Renehan A, Gleave EN, Hancock BD, Smith $\mathrm{P}$ and Gurk M, found out male-female ratio to be 1.2:1.5 In our study, both benign and malignant tumours were found to be common in female with male-female ratio of $1: 1.58$ and 1:1.25 respectively. Study by Laishram RS et al, where benign tumour was common in male population with a ratio of 1.04:1 and malignant tumour in female with ratio of 1:3.14.6

Parotid gland involvement was the commonest, seen in $87.5 \%$ cases. Submandibular and minor salivary gland (Sublingual) involvement was found to be $10 \%$ and $2.5 \%$ respectively. Study by Eveson JW and Cawson RA, parotid involvement was seen in $72.9 \%$ cases, submandibular in $10.7 \%$ and sublingual $0.3 \%{ }^{4}$ Another study by De Oliveira FA, Duarate FC, Tavera CT, Maximo AA, de-Aquino EC and Alencar $\mathrm{RD}$ parotid involvement was seen in $69.5 \%$ cases, submandibular in $15.8 \%$ and sublingual in $14.7 \%{ }^{7}$

In the present study, $80 \%$ tumours were found to be benign and other $20 \%$ were malignant. Comparative study by Renehan A, Gleave EN, Hancock BD, Smith P and Gurk M, benign and malignant tumour were found to be $79.6 \%$ and 20.4\% respectively. ${ }^{5}$ Study by Pablo Augustin Vargas, Rene Gerhard Vergilius JF Arayo, Filho, Ihes Viera de Castro, benign and malignant tumour were found to be $80 \%$ and $20 \%$ respectively. 8

It was found that among the malignant tumours, $87.5 \%$ involvement was seen in parotid gland and $12.5 \%$ in submandibular gland. Study by Laishram RS et al found, parotid (59.09\%) was the commonest gland involved by malignancy followed by submandibular $(27.27 \%)$ and minor salivary gland (13.64\%). ${ }^{6}$ Present study shows predominant involvement of parotid gland in malignant lesion than submandibular gland.

Regarding clinical presentation all cases presented with swelling of the glands, $5 \%$ with facial nerve palsy, $15 \%$ cases with pain in that gland, $2.5 \%$ cases with cervical lymph node 
enlargement and $2.5 \%$ with deep lobe involvement. Spiro RH et al reported incidence of pain, facial nerve, cervical lymph node in malignant tumours as $10 \%, 22 \%$ and $23 \%$ respectively. Also in that study, all cases presented with swelling of the glands. ${ }^{2}$ From this it is seen that swelling is the commonest symptom. Pain, facial palsy, lymph node involvement, fixity and deep lobe involvement suggests malignancy.

In the present study after histological confirmation $67.5 \%$ cases were found to be pleomorphic adenoma, 20\% mucoepidermoid carcinoma, 7.5\% Warthin's tumour, 2,5\% basal cell adenoma and remaining $2.5 \%$ cases were found to be adenoid cystic carcinoma. Comparative study by Pablo Augustin Vargas, Rene Gerhard Vergilius JF Arayo, Filho and Ihes Viera de Castro reported $67.7 \%$ cases to be pleomorphic adenoma, $10.48 \%$ mucoepidermoid carcinoma, $10.48 \%$ Warthin's tumour, $0.4 \%$ adenoid cystic carcinoma and $0.2 \%$ reported to be carcinoma ex-pleomorphic adenoma. ${ }^{8}$

After confirmation of diagnosis during management, Superficial Parotidectomy was the commonly followed procedure for salivary gland tumour in this study $(52.5 \%$ cases) followed by total parotidectomy (20\%). Radical parotidectomy was the least commonly followed $(2.5 \%)$ procedure. Commonest procedure as quoted by Leverstein $\mathrm{H}$ et al was 'partial' superficial parotidectomies (53.25\%) followed by 'total' superficial parotidectomies (24.79\%) and total parotidectomies (3.25\%) during management. ${ }^{9}$

Most commonly encountered complication in the postoperative cases was facial nerve palsy $(20 \%)$, which is temporary followed by Frey's syndrome (7.5\%), wound infection (5\%), haemorrhage/haematoma (5\%) and least commonly encountered complication was permanent palsy of facial nerve $(2.5 \%)$. Owen ERTC et al reported most common complication to be facial nerve palsy (38\%) followed by Frey's syndrome $(11 \%)$ and fistula (2\%).10

\section{CONCLUSION}

To conclude, salivary gland neoplasms are not common. Parotid gland was found to be the principal site for salivary gland tumours in this part of Assam and pleomorphic adenoma was found to be the commonest tumour of salivary gland. In our study, we found female to be more commonly affected than male in both benign and malignant tumour group. To determine the prevalence, larger studies are needed.

\section{REFERENCES}

1. Stenner M, Klussmann JP. Current update on established and novel biomarkers in salivary gland carcinoma pathology and the molecular pathways involved. Eur Arch Otorhinolaryngol 2009;266(3):333-41.

2. Spiro RH. Salivary neoplasms: overview of a 35-year experience with 2,807 patients. Head Neck Surg 1986;8(3):177-84.

3. Li LJ, Li Y, Wen YM, et al. Clinical analysis of salivary gland tumour cases in west China in past 50 years. Oral Oncol 2008;44(2):187-92.

4. Eveson JW, Cawson RA. Salivary gland tumours, a review of 2410 cases with particular reference to histological types, sites, age and sex distribution. Journal of Pathology 1985; 146(1):51-8.

5. Renehan A, Gleave EN, Hancock BD, et al. Long-term followup of over 1000 patients with salivary gland tumours treated in a single centre. Br J Surgery 1996;83(12): 1750-4.

6. Laishram RS, Kumar KA, Pukhrambam GD, et al. Pattern of salivary gland tumours in Manipur, India: a 10-year study. South Asian J Cancer 2013;2(4):250-3.

7. De Oliveira FA, Duarte ECB, Taveira CT, et al. Salivary gland tumour, a review of 599 cases in a Brazilian population. Head and Neck Pathology 2009;3(4):271-5.

8. Vargas PA, Gerhard R, Filho AVJ, et al. Salivary gland tumours in a Brazilian population: a retrospective study of 124 cases. Rev Hosp Clin Fac Med São Paulo 2002; $57(6): 271-6$.

9. Leverstein H, van der Wal JE, Tiwari RM, et al. Surgical management of 246 previously untreated pleomorphic adenomas of the parotid gland. British Journal of Surgery 1997;84(3):399-403.

10. Owen ER, Banerjee AK, Kissin M, et al. Complications of parotid surgery: the need for selectivity. British Journal of Surgery 1989;76(10):1034-5. 